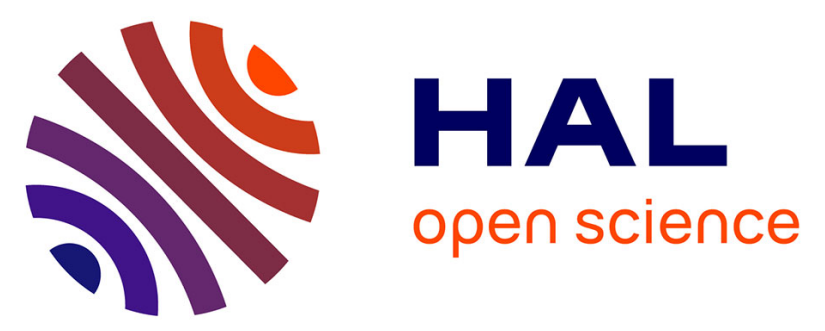

\title{
Analysis of InGaN surfaces after chemical treatments and atomic layer deposition of Al2O3 for uLED applications
}

\author{
Corentin Le Maoult, David Vaufrey, François Martin, Eugénie Martinez, \\ Emmanuel Nolot, Stéphane Cadot, Etienne Gheeraert
}

\section{To cite this version:}

Corentin Le Maoult, David Vaufrey, François Martin, Eugénie Martinez, Emmanuel Nolot, et al.. Analysis of InGaN surfaces after chemical treatments and atomic layer deposition of $\mathrm{Al} 2 \mathrm{O} 3$ for uLED applications. Proceedings of SPIE, the International Society for Optical Engineering, 2020, 11280, pp.112801C. $10.1117 / 12.2544787$. cea-02941396v2

\section{HAL Id: cea-02941396 https://hal-cea.archives-ouvertes.fr/cea-02941396v2}

Submitted on 25 Sep 2020

HAL is a multi-disciplinary open access archive for the deposit and dissemination of scientific research documents, whether they are published or not. The documents may come from teaching and research institutions in France or abroad, or from public or private research centers.
L'archive ouverte pluridisciplinaire HAL, est destinée au dépôt et à la diffusion de documents scientifiques de niveau recherche, publiés ou non, émanant des établissements d'enseignement et de recherche français ou étrangers, des laboratoires publics ou privés. 

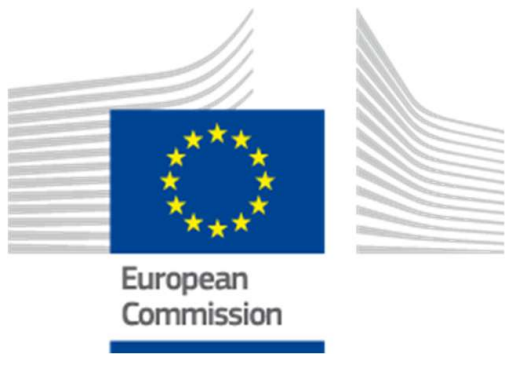

European

\begin{tabular}{|c|c|}
\hline Document Title & $\begin{array}{l}\text { Analysis of InGaN surfaces after chemical treatments } \\
\text { and atomic layer deposition of } \mathrm{Al}_{2} \mathrm{O}_{3} \text { for } \mu \text { LED } \\
\text { applications }\end{array}$ \\
\hline Authors & $\begin{array}{l}\text { Corentin Le Maoulta, David Vaufrey }{ }^{\mathrm{a}} \text {, François Martina }{ }^{\mathrm{a}} \text { Eugénie } \\
\text { Martinez }^{\mathrm{a}} \text {, Emmanuel Nolot }{ }^{\mathrm{a}} \text {, Stéphane Cadota } \\
\\
\text { aUniv. Etienne Gheeraert } \\
\text { bUniv. Grenoble Alpes, CEA, LETI, F-38000 Grenoble, France; } \\
\text { Grenoble, France }\end{array}$ \\
\hline Issue date & February 16, 2020 \\
\hline Journal & $\begin{array}{l}\text { Proceedings Volume 11280, Gallium Nitride Materials and Devices } \\
\text { XV; } 112801 \mathrm{C} \text { (2020) }\end{array}$ \\
\hline Doi & $10.1117 / 12.2544787$ \\
\hline Acknowledgment & $\begin{array}{l}\text { This project has received funding from the Clean Sky } 2 \text { Joint } \\
\text { Undertaking under the European Union's Horizon } 2020 \text { research } \\
\text { and innovation programme under grant agreement No } 755497 .\end{array}$ \\
\hline Disclaimer & $\begin{array}{l}\text { The content of this article reflects only the author's view. } \\
\text { The Clean Sky Joint Undertaking is not responsible for any use that } \\
\text { may be made of the information it contains. }\end{array}$ \\
\hline
\end{tabular}




\title{
Analysis of InGaN surfaces after chemical treatments and atomic layer deposition of $\mathrm{Al}_{2} \mathrm{O}_{3}$ for $\mu \mathrm{LED}$ applications
}

\author{
Corentin Le Maoult ${ }^{a}$, David Vaufrey ${ }^{a}$, François Martin ${ }^{a}$, Eugénie Martinez ${ }^{a}$, Emmanuel Nolot $^{a}$, \\ Stéphane Cadot $^{\mathrm{a}}$, Etienne Gheeraert ${ }^{\mathrm{b}}$ \\ ${ }^{a}$ Univ. Grenoble Alpes, CEA, LETI, F-38000 Grenoble, France; ${ }^{b}$ Univ. Grenoble Alpes, CNRS, \\ Grenoble INP*, Institut Néel, 38000 Grenoble, France
}

\begin{abstract}
A deep understanding of semiconductors-dielectrics interface properties will provide guidelines to optimize efficient passivation solutions for $\mathrm{InGaN} / \mathrm{GaN}$ based $\mu \mathrm{LED}$. To this end, the quantum wells (QW) semiconductor is of tremendous interest since a lot of surface recombinations are likely to occur at LED active regions edges and are probably responsible for the low $\mu \mathrm{LED}$ efficiencies. Thus we discuss in this paper about X-ray photoemission (XPS) and wavelength dispersive $\mathrm{X}$-ray fluorescence (WDXRF) characterizations of $\mathrm{In}_{0.1} \mathrm{Ga}_{0.9} \mathrm{~N}$ surfaces after acid, basic or sulfur based chemical treatments followed or not by atomic layer deposition (ALD) of $\mathrm{Al}_{2} \mathrm{O}_{3}$ thin films with $\mathrm{TMA} / \mathrm{H}_{2} \mathrm{O}$ or $\mathrm{TMA} / \mathrm{O}_{2}$ plasma (plasma enhanced ALD) at $250^{\circ} \mathrm{C}$.

Depending on chemical treatments, variations of indium related XPS peaks were observed, which did not seem to be significantly affected by deposition of $\mathrm{Al}_{2} \mathrm{O}_{3}$ whatever the oxidizing precursor. The extreme surface concentration of indium was probably reduced, suggesting that some chemical pre-treatments for cleaning or passivation steps would have a direct impact on InGaN QW properties at LED edges.

After sulfur based chemical treatments, even if sulfur was hardly detected by XPS, complementary measurements by WDXRF and subsequent calibration of the sulfur signal supported evaluation of a low surface concentration of sulfur.

Changes of $\mathrm{Al}_{2} \mathrm{O}_{3}$ related XPS peaks suggested that the various studied pre-treatments induced different nucleations of first ALD cycles. Then, a clear variation of $\mathrm{InGaN}$ surfaces hydrolysis depending on surface treatments was finally highlighted by WDXRF based counting measurements, opening the way to a better understanding of first $\mathrm{Al}_{2} \mathrm{O}_{3}$ layers nucleation on $\mathrm{InGaN}$.
\end{abstract}

Keywords: * $\mu \mathrm{LED}, \mathrm{InGaN}$ passivation, XPS-WDXRF, $\mathrm{Al}_{2} \mathrm{O}_{3}-\mathrm{ALD}$ or $\mathrm{PEALD}$, surface treatments*

\section{INTRODUCTION}

III-V materials have allowed the development of very efficient blue planar light emitting diodes (LED) for display or lighting applications. Because of relatively new applications such as micro-displays, LED miniaturization is becoming an attractive challenge of recent years in optoelectronics. Especially since micro-sized GaN/InGaN LED ( $\mu$ LED) seem to offer very promising properties particularly adapted to this field.

Indeed, according to the literature, $\mu \mathrm{LED}$ would allow good viewing angles ${ }^{1}$ and would handle higher current densities than macro-LED, presumably thanks to better current and thermal managements in devices. Consequently, $\mu \mathrm{LED}$ would be capable of reaching higher optical output power densities than macro-LED ${ }^{2-6}$. However, extraction efficiency would also have to be considered at this point (some optical modes are strongly geometry and dimensions dependent). Some discussions report also about $\mathrm{GaN} / \mathrm{InGaN}$ strain constraint relaxations in $\mu \mathrm{LED}^{6-8}$ comparatively to macro-LED. All these considerations being still under debate.

However, huge luminescence efficiency decreases have been observed for $\mu L E D$, presumably attributed to etching related sidewalls defects states and size effects $5,9,10$. Besides optimizing etching processes to limit sidewalls defects generation, the development and the optimization of passivation post-processing steps seem to be mandatory at this point. Thus, it represents a key point of interest since efficient $\mu \mathrm{LED}$ sidewall passivation solutions would allow to significantly improve the current $\mathrm{GaN} / \mathrm{InGaN} \mu \mathrm{LED}$ technology.

Some research teams already presented LED passivation related solutions. During the first decade of the 2000s, first examples of LED efficiency improvements after deposition of $\mathrm{SiN}^{11}, \mathrm{SiON}^{12}$ or even $\mathrm{Al}_{2} \mathrm{O}_{3}{ }^{13}$ layers could be found in literature. A better extraction was achieved using the thin dielectric layers as an optical index adaptation tool. Later, Yang 
et al. ${ }^{14}$ and $\mathrm{Guo}$ et al. ${ }^{15}$ presented first detailed studies of $\mathrm{Al}_{2} \mathrm{O}_{3}$ deposition effects on $\mathrm{LED}$ electrical properties. While they added a top $\mathrm{SiO}_{2}$ layer mainly for extraction considerations, it was shown that $\mathrm{ALD}$ or PEALD of $\mathrm{Al}_{2} \mathrm{O}_{3}$ from their $\mathrm{Al}_{2} \mathrm{O}_{3}$ $\mathrm{SiO}_{2}$ stacks allowed LED electro-optical properties improvements thanks to surface states densities lowering. Another document also reports the passivation efficiency of $\mathrm{SiO}_{2}-\mathrm{Si}_{3} \mathrm{~N}_{4}$ stacks deposited by PECVD ${ }^{16}$ despite the plasma deposition. Finally, Wong et al. ${ }^{17}$ were the first to demonstrate an improved efficiency on $\mu \mathrm{LED}$ after $\mathrm{ALD}$ of $\mathrm{SiO}_{2}$, and highlighted the importance of using preferentially ALD method rather than PECVD. Very recently, for LED holes injections related problematics, Kim et al. ${ }^{18}$ managed to control the bands bending of $\mathrm{p}-\mathrm{GaN}$ surface after ALD of AlN$\mathrm{Al}_{2} \mathrm{O}_{3}$ stacks. A clear improvement of their LED efficiency was achieved thanks to a better $\mathrm{p}-\mathrm{GaN}$ passivation coupled to an increased holes injection efficiency in the LED active region.

These first LED passivation-related works are often focused on extraction problematics and mostly concern macrosized LED. Few of them treat exclusively of $\mu$ LED passivation issues. In this context, detailed studies focusing separately on LED semiconductors surface properties after typical passivation steps will undoubtedly provide solid, complementary and helpful knowledge to go further in developing the best passivation solution for $\mathrm{GaN} / \mathrm{InGaN} \mu \mathrm{LED}$. Due to their different compositions or doping natures, transport layers and active region semiconductors from LED structures cannot be handle similarly for passivation problematics. Indeed, LED stacks include several semiconductors such as negatively doped $\mathrm{GaN}(\mathrm{n}-\mathrm{GaN})$, positively doped $\mathrm{GaN}(\mathrm{p}-\mathrm{GaN}), \mathrm{AlGaN}$ as electron blocking layer $(\mathrm{EBL})$ and $\mathrm{InGaN}$ for the active region's QW.

Whether being bulk or surfaces related, Shockley-Read-Hall (SRH) non-radiative phenomena rate directly depends on the nature and concentration of the defects in LED and on charges carriers concentrations ${ }^{19}$.

Bulk defects proportion in LED mainly depends on epitaxy quality. On the contrary, surfaces defects mainly originate from etching steps (besides being also the natural consequence of inevitable dangling bonds at the surface). For $\mu L E D$, the high perimeter to surface ratio is responsible for an increased sensitivity to surface defects and thus to the SRH associated recombinations.

Numerical simulation results, displayed in figure 1, confirm that SRH recombinations mainly occur in LED stack layers with high hole and electron concentration overlapping. Consequently, $\mathrm{SRH}$ recombination rate is higher in quantum wells since obviously the LED bandgap engineering concentrates opposite sign carriers in InGaN layers to optimize the radiative recombinations. Due to electronic overflow and $\mathrm{GaN}$ p-doping difficulties, the p-doped transport layers present a relatively high minority charge carrier concentration comparatively to the $\mathrm{n}-\mathrm{GaN}$ layers. Therefore, InGaN from the active region would have to be considered preferentially for passivation problematics. Then, the $\mathrm{p}-\mathrm{GaN}$ and finally the $\mathrm{n}-\mathrm{GaN}$.

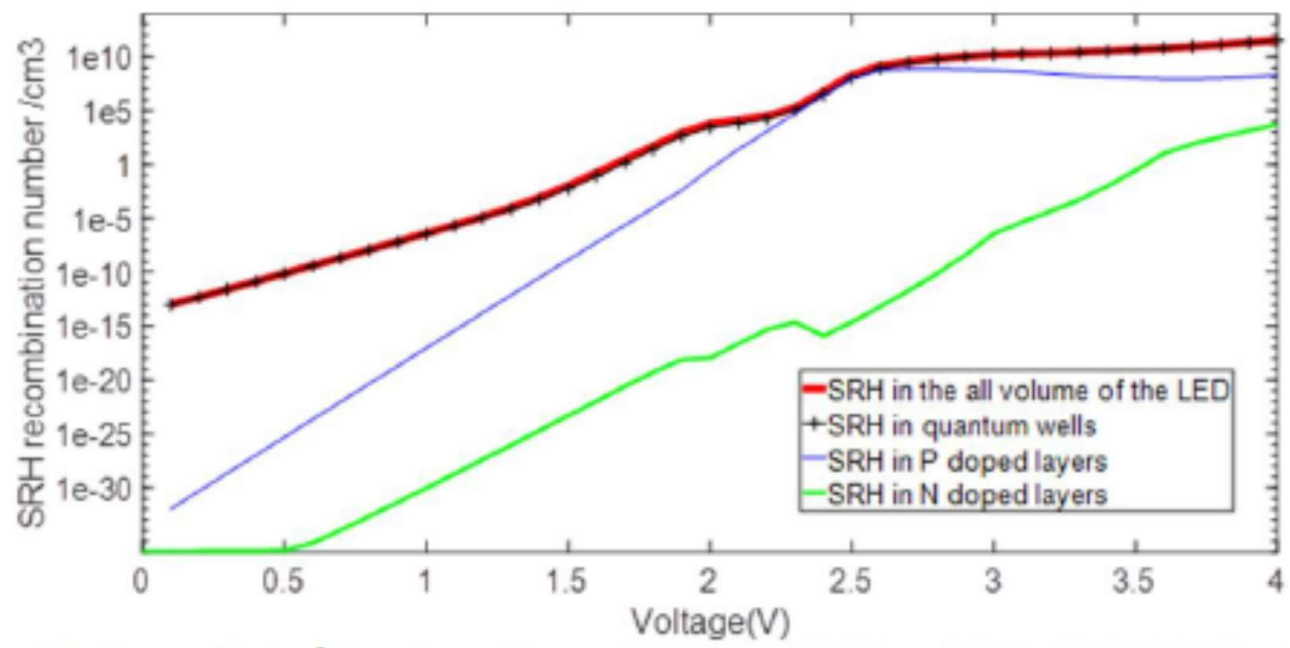

Fig. 1. SRH recombination number $/ \mathrm{cm}^{3}$ in various volumes of a $\mathrm{GaN}$ based LED modelled with ATLAS from Silvaco

Regarding dielectric materials, as previously mentioned, scientific publications underline the potential effectiveness of $\mathrm{SiO}_{2}$ or $\mathrm{Al}_{2} \mathrm{O}_{3}$ for $\mathrm{LED}$ sidewall passivation. Additionally, the passivating action of alumina over $\mathrm{GaN}$ surfaces is often reported for power transistor applications, especially when oxidizing reactant is tuning the bandgap value and leakage characteristics of alumina ( $\mathrm{ALD}$ versus $\mathrm{PEALD})^{20} . \mathrm{Al}_{2} \mathrm{O}_{3}$ and $\mathrm{SiO}_{2}$ have a large band gap $\left(\mathrm{E}_{\mathrm{g}} \sim 7-9 \mathrm{eV}\right.$ ), large conduction and valence bands offsets (respectively $\sim 2.1 \mathrm{eV}$ and $\sim 2.5 \mathrm{eV}$ for $\mathrm{Al}_{2} \mathrm{O}_{3}, \sim 3.6 \mathrm{eV}$ and $\sim 2 \mathrm{eV}$ for $\mathrm{SiO}_{2}{ }^{21}$ ) and an $1.8(1.48$ for $\mathrm{SiO}_{2}$ ) optical index (at $450 \mathrm{~nm}$ ), which could be valuable for internal reflection in $\mathrm{LED}\left(\mathrm{n}_{\mathrm{GaN}(450 \mathrm{~nm})} \sim 2.49\right)$. The free Gibbs 
energy of $\mathrm{Al}_{2} \mathrm{O}_{3}$ formation reaction $\left(-1582 \mathrm{~kJ} \cdot \mathrm{mol}^{-1}\right)$ is also higher than $\mathrm{Ga}_{2} \mathrm{O}_{3}$ value for example $\left(-998 \mathrm{~kJ} \cdot \mathrm{mol}^{-1}\right)^{22}$. Finally, $\mathrm{ALD} \mathrm{Al} \mathrm{O}_{3}$ is a well-known deposition process and is also recognized as non surface-damaging method. Besides allowing a very precise thickness control, uniform and homogeneous nanometer-thick layers can be deposited with ALD on surfaces with low or high aspect ratio factors. For all these reasons, ALD alumina seems to be particularly suitable for LED sidewalls passivation problematics, provided $\mathrm{Al}_{2} \mathrm{O}_{3}$ reactant would be chosen after evaluation of its oxidizing power over LED stack semiconductor's $\left(\mathrm{H}_{2} \mathrm{O}, \mathrm{O}_{3}, \mathrm{O}_{2}\right.$ plasma...).

This document deals with surfaces properties of $\operatorname{InGaN}$ after standard surface chemical treatments such as $\mathrm{HCl}$ or $\mathrm{NH}_{4} \mathrm{OH}$ before $\mathrm{ALD}$ of $\mathrm{Al}_{2} \mathrm{O}_{3}$ using different oxidizing reactants. Effects of $\left(\mathrm{NH}_{4}\right)_{2} \mathrm{~S}$ surface treatments are also evaluated, since several scientific publications report the sulfur passivating action effectiveness over $\mathrm{GaN}$ surfaces, presumably strongly dependent on experimental conditions ${ }^{23}$. Indeed, InGaN surface study allows us to investigate in the same time, gallium and indium evolution induced by surface treatment and/or ALD process. In particular, this study focus on indium and gallium oxidation and stoichiometry. Indeed, indium oxide is amphoteric, could act as a metal or as a semiconductor and consequently is expected to induce parasitic surface states. Equally, five polymorphs of gallium oxide are commonly identified and can be either insulators or conductors, depending on the growth conditions ${ }^{24,25}$. So, gallium oxide is also expected to induce parasitic surface states.

Furthermore, this study also focus on surface hydrolysis which promote dielectric nucleation such as $\mathrm{ALD}_{2} \mathrm{O}_{3}$. For this purpose, our investigations are based on $\mathrm{X}$-ray photoelectron spectroscopy and high resolution wavelength dispersive $\mathrm{X}$ ray fluorescence techniques, particularly adapted to surface qualitative or quantitative analysis.

\section{EXPERIMENTAL}

All experiments were performed on unpatterned and undoped samples with a $200 \mathrm{~nm} \operatorname{In}_{\mathrm{n}} \mathrm{Ga}_{1-\mathrm{x}} \mathrm{N}$ top layer $(x \approx 10 \%)$ deposited on $\mathrm{GaN}$ buffer and sapphire substrates.

All samples were first cleaned using standard solvent solutions (acetone, ethanol then isopropyl alcohol). In the rest of the present document, samples at this stage will be referred as "as-received" samples. The $\left.\mathrm{HCl}_{(\mathrm{NH}} \mathrm{OH}\right)$ treatments consisted in dipping samples in a mixture of $37 \% \mathrm{HCl}\left(29 \% \mathrm{NH}_{4} \mathrm{OH}\right)$ diluted 10 times in deionized (DI) water for 10 minutes at $300 \mathrm{~K}$. After treatments, samples were rinsed in DI water.

Sulfur chemical treatments were performed for 5 or 30 minutes in undiluted $20 \%\left(\mathrm{NH}_{4}\right)_{2} \mathrm{~S}$ solutions at ambient temperature, after or not a first $\mathrm{NH}_{4} \mathrm{OH}$ treatment. Different rinsing durations in DI water were implemented after the $\left(\mathrm{NH}_{4}\right)_{2} \mathrm{~S}$ treatments (as well as an IPA rinsing successively to a first DI water rinsing for one sample). Some reference samples were also exposed to sulfur using reaction at higher temperature.

Atomic layer depositions of $\mathrm{Al}_{2} \mathrm{O}_{3}$ were all performed at $250^{\circ} \mathrm{C}$ using Oxford Fiji tool. The metallic precursor was trimethyl-aluminum (TMA). The oxidizing reactant was water $\left(\mathrm{H}_{2} \mathrm{O}\right)$ for thermal-based processes and oxygen radicals generated by the deported plasma for the $\mathrm{O}_{2}$-plasma processes.

Three-nanometers thick layers were deposited to allow the characterization of $\mathrm{InGaN} / \mathrm{Al}_{2} \mathrm{O}_{3}$ interface by XPS measurements, given the limited sampling depth of XPS. Considering ALD equipment calibrations, it was equivalent to 30 cycles of $\mathrm{ALD}\left(\mathrm{H}_{2} \mathrm{O}\right.$ first) and to 33 cycles of PEALD (TMA first). Sequences between surface treatments and $\mathrm{Al}_{2} \mathrm{O}_{3}$ deposition were all completed in less than 5 minutes with an air break

The thermal treatments were realized in a rapid thermal annealing furnace at $400^{\circ} \mathrm{C}$ during 15 minutes under dinitrogen atmosphere $\left(\mathrm{N}_{2}\right)$, additionally to a 2 minutes long temperature rise and to 6 minutes of cooling.

XPS analyses were carried out with a spectrometer from Scienta Omicron equipped with a monochromated A1 K $\alpha$ source $(\mathrm{h} v=1486.7 \mathrm{eV}$ ) and installed at the NanoCharacterization PlatForm (PFNC) of Minatec (Grenoble, France). Experiments were performed under ultra-high vacuum $\left(\mathrm{P}=10^{-9} \mathrm{mbar}\right)$. Photoelectrons were collected by a hemispherical analyzer at pass energy of $15 \mathrm{eV}$ leading to an overall energy resolution of $350 \mathrm{meV}$. All XPS analyses were done with a $80^{\circ}$ angle between samples surfaces and analyzer; $1 \mathrm{eV}$ of flood-gun was applied to prevent surface from overcharging because of atoms ionization.

The $\mathrm{C} 1 \mathrm{~s}, \mathrm{Ga} 3 \mathrm{~d}, \mathrm{In} 3 \mathrm{~d}, \mathrm{~N} 1 \mathrm{~s}$ and $\mathrm{O} 1 \mathrm{~s}$ photoemission lines were collected for all samples. A12p and/or S2p and S2s lines were added respectively after $\mathrm{Al}_{2} \mathrm{O}_{3}$ deposition and/or after sulfured surface treatments. All XPS spectra were energy corrected referring to the $\mathrm{C} 1 \mathrm{~s}$ line fixed at $284.8 \mathrm{eV}$. Quantitative analyses were performed after XPS spectra decompositions with the software CASAXPS, using Voigt functions and after adapted background subtraction. All energy lines subject to spinorbit energy states splitting were decomposed using constrained doublets components. 
The $\mathrm{C} 1 \mathrm{~s}$ line was decomposed using three components representative of $\mathrm{C}-\mathrm{C}, \mathrm{C}-\mathrm{O}$ or $\mathrm{O}-\mathrm{C}=\mathrm{O}$ bonding. Then, two contributions representative of $\mathrm{GaN}(-\mathrm{In})$ and $\mathrm{InN}(-\mathrm{Ga})$ species with two additional oxide components $\left(\mathrm{Ga}_{\mathrm{x}} \mathrm{O}_{y}\right.$ and $\mathrm{In}_{\mathrm{x}} \mathrm{O}_{y}$, respectively constrained at $+0.8 \mathrm{eV}$ and $+0.6 \mathrm{eV}$ ) were added respectively for $\mathrm{Ga} 3 \mathrm{~d}$ and In $4 \mathrm{~d}$ lines decompositions. Finally, two components representative of $\mathrm{N} 2 \mathrm{~s}$ and $\mathrm{O} 2 \mathrm{~s}$ lines were added near the Ga3d spectra respectively at lower and higher energies (O2s for $\mathrm{Al}_{2} \mathrm{O}_{3}$ capped surfaces only). The In $3 \mathrm{~d}$ doublet was decomposed in two main components similarly to the In $4 d$ doublet $\left(\operatorname{In}_{x} \mathrm{O}_{y}\right.$ and $\left.\operatorname{InN}(-\mathrm{Ga})\right)$. Due to the strong interference of the N1s line with gallium Auger peaks when the Al $\mathrm{K} \alpha$ XPS source is used, nitrogen is not discussed in this paper. The O1s peak has been decomposed using three components accounting for oxygen-metalloid bonding ( $\mathrm{O}-\mathrm{Ga}$ and $\mathrm{O}-\mathrm{In}), \mathrm{O}-\mathrm{C} / \mathrm{O}-\mathrm{H}$ and $\mathrm{O}=\mathrm{C}$ bonding, respectively in the increased binding energy order. With the $\mathrm{Al}_{2} \mathrm{O}_{3}$ dielectric layer, the peak composition was evolving in two main contributions representative of $\mathrm{Al}_{2} \mathrm{O}_{3}$ and of $\mathrm{Al}-\mathrm{OH}$ related species ${ }^{26}$ at higher energy (constrained to $+1.4 \mathrm{eV}$ from the $\mathrm{Al}_{2} \mathrm{O}_{3}$ component). Note that $\mathrm{O}-\mathrm{C}$ bonding from hydrocarbon contamination can also contribute to the higher energy peak. The $\mathrm{Al} 2 \mathrm{p}$ peak was decomposed using a main contribution representative of $\mathrm{Al}_{2} \mathrm{O}_{3}$ signal. In some cases, another component could be possibly added at high energy with respect to the $\mathrm{Al}_{2} \mathrm{O}_{3}$ peak, representative of $\mathrm{Al}(\mathrm{OH})_{3} \mathrm{species}^{27}$.

The S2p line is strongly interfering with the Ga3s line and with the associated gallium oxide. Consequently, the main $\mathrm{S} 2 \mathrm{p} 3 / 2$ peak of the $\mathrm{S} 2 \mathrm{p}$ doublet was constrained between $163,5 \mathrm{eV}$ and $164,5 \mathrm{eV}$. When visible, the $\mathrm{S} 2 \mathrm{~s}$ line was decomposed in two main components, possibly representative of $\mathrm{Ga}-\mathrm{S}$ or $\mathrm{In}-\mathrm{S}$ related species.

The growth of $\mathrm{ALD} \mathrm{Al} \mathrm{O}_{3}$ depends on the presence of $-\mathrm{OH}$ species at samples surfaces. Therefore, the counting of aluminum atoms chemisorbed after a first TMA exposition can be representative of the initial $\mathrm{OH}$ surface concentration (or surface hydrolysis). This quantitative analysis was performed using WDXRF measurements on InGaN surfaces after 1,3 or $6 \mathrm{ALD}$ cycles (TMA $1^{\text {th }}$ ) and depending on surface treatments $\left(\mathrm{HCl}, \mathrm{NH}_{4} \mathrm{OH}\right.$ or $\left(\mathrm{NH}_{4}\right)_{2} \mathrm{~S}$ pre-treatments).

Complementary surface quantitative analysis of sulfur treated samples was performed by WDXRF measurements. A $3 \mathrm{~nm} \mathrm{ZnS}$ reference is used for sulfur calibration to estimate deconvolution validity, since a $4^{\text {th }}$ diffraction order of the $\mathrm{Ga}$ $\mathrm{K} \alpha$ line was interfering with the studied $\mathrm{S} \mathrm{K} \alpha$ line. Some "as-received" reference samples treated by the higher sulfidation temperature process are used for XPS calibration of $\left(\mathrm{NH}_{4}\right)_{2} \mathrm{~S}$ treated samples as well.

In-line wavelength-dispersive X-ray fluorescence (WDXRF) experiments were carried out in the primary-vacuum chamber of Rigaku AZX400 tool. The samples were irradiated with the polychromatic radiation of a Rhodium tube operated at $30 \mathrm{kV}$ and $100 \mathrm{~mA}$. We selected these conditions in order to enhance the intensity of Rhodium $\mathrm{L}$ lines $(\mathrm{L} \alpha$ at $2.697 \mathrm{keV}$ ), thereby increasing the sensitivity to sulfur (using S-K $\alpha$ line) and aluminum (with Al-K $\alpha$ line). We used Ge (111) crystal (resp. a PET crystal) mounted on a high-resolution goniometer to select the wavelengths related to $\mathrm{S}-\mathrm{K} \alpha$ (resp. Al-K $\alpha$ line). Then, the X-ray fluorescence intensities were recorded with a gas flow type proportional counter. We used fundamental parameters approach ${ }^{28}$ to quantify the deposited mass of aluminum. The sensitivity factor of the WDXRF tool was deduced from the measurement of a pure aluminum target.

\section{XPS AND WDXRF STUDY OF INGAN SURFACE TREATMENT}

\subsection{Comparison of $\mathrm{InGaN}$ surfaces after $\mathrm{HCl}$ or $\mathrm{NH}_{4} \mathrm{OH}$ chemical treatments}

An important variation of the In4d peak intensities near the $\mathrm{Ga} 3 \mathrm{~d}$ spectra (fig. 2a) is evidenced after the $\mathrm{HCl}$ or $\mathrm{NH}_{4} \mathrm{OH}$ chemical treatments, and especially after $\mathrm{HCl}$.

The quantitative analysis summarized in figure 3 reports a total indium relative atomic concentration estimated at approximatively 13 at.\% for as-received samples decreasing until 12 at. $\%$ and 5 at.\%, respectively after $\mathrm{NH}_{4} \mathrm{OH}$ and $\mathrm{HCl}$ treatments. Similar trends are observed whether analysis is done using In $3 \mathrm{~d}$ or In $4 \mathrm{~d}$ photoemission lines (fig. 3). Oxygen levels seem to decrease from 10 at. $\%$ for the as-received sample to about 8 at. $\%$ and 5 at. $\%$ with $\mathrm{NH}_{4} \mathrm{OH}$ and $\mathrm{HC} 1$ treatments respectively (fig. 3).

In comparison, gallium atomic concentration and oxide level do not significantly change according to the proposed decompositions and to the resulting quantitative analysis detailed in figure 3 (the gallium content is however increased for $\mathrm{HCl}$ treated sample, consequently to indium depletion). The same ascertainment can be done for oxidized carbon contributions, even if a slight decrease can be noted for $\mathrm{HCl}$ treated sample.

Consequently, indium and oxygen intensities attenuations could be partially induced by the decrease of indium oxidation level. This is consistent with the In $3 \mathrm{~d}$ shape evolutions. Indeed, as illustrated in figure $2 \mathrm{~b}$, indium is initially quite oxidized since we have relatively symmetrical and broad peaks, while a much thinner and asymmetrical contribution 
seems to dominate at lower energy after both chemical treatments. Moreover, the low energy O1s contribution generally representative of oxygen-metalloids bonding is attenuated after both chemical treatments but especially after $\mathrm{HCl}$ (fig. $2 \mathrm{c}$ ).

(a) Ga3d \& In $4 d$

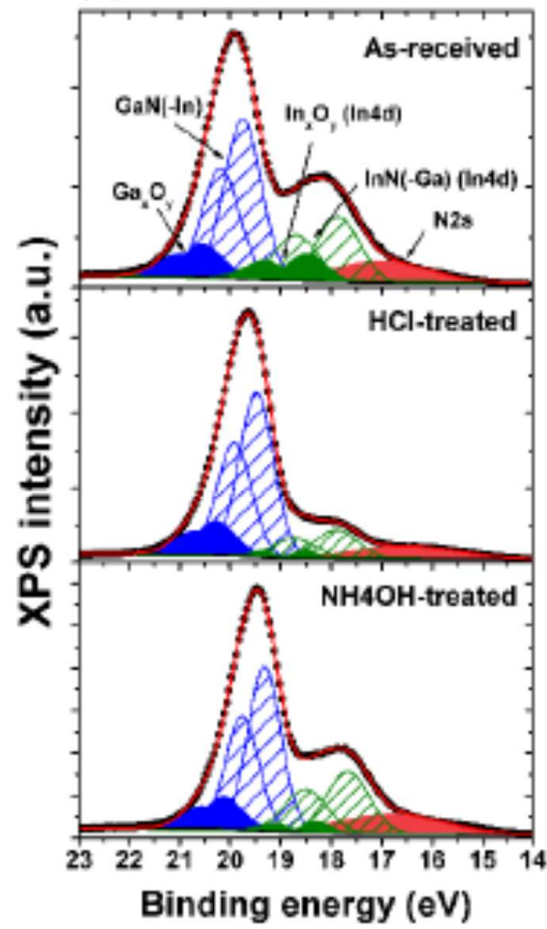

(b) $\ln 3 d$

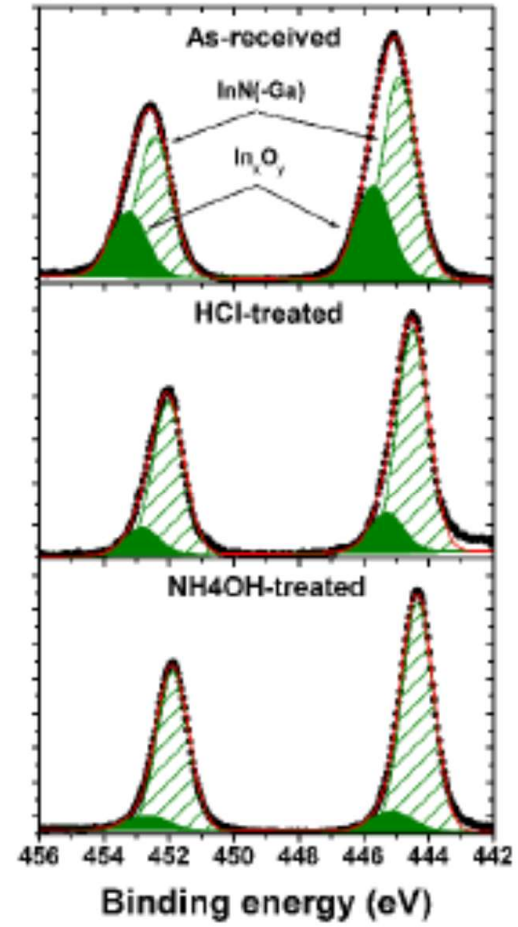

(c) $01 \mathrm{~s}$

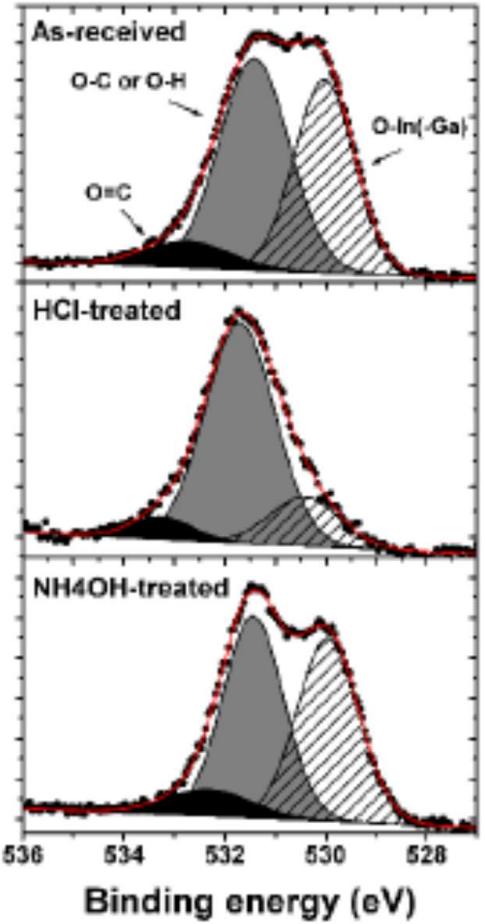

Fig. 2. Ga3d \& In4d (a), In3d (b), Ols (c) spectra after $\mathrm{HCl}$ or $\mathrm{NH}_{4} \mathrm{OH}$

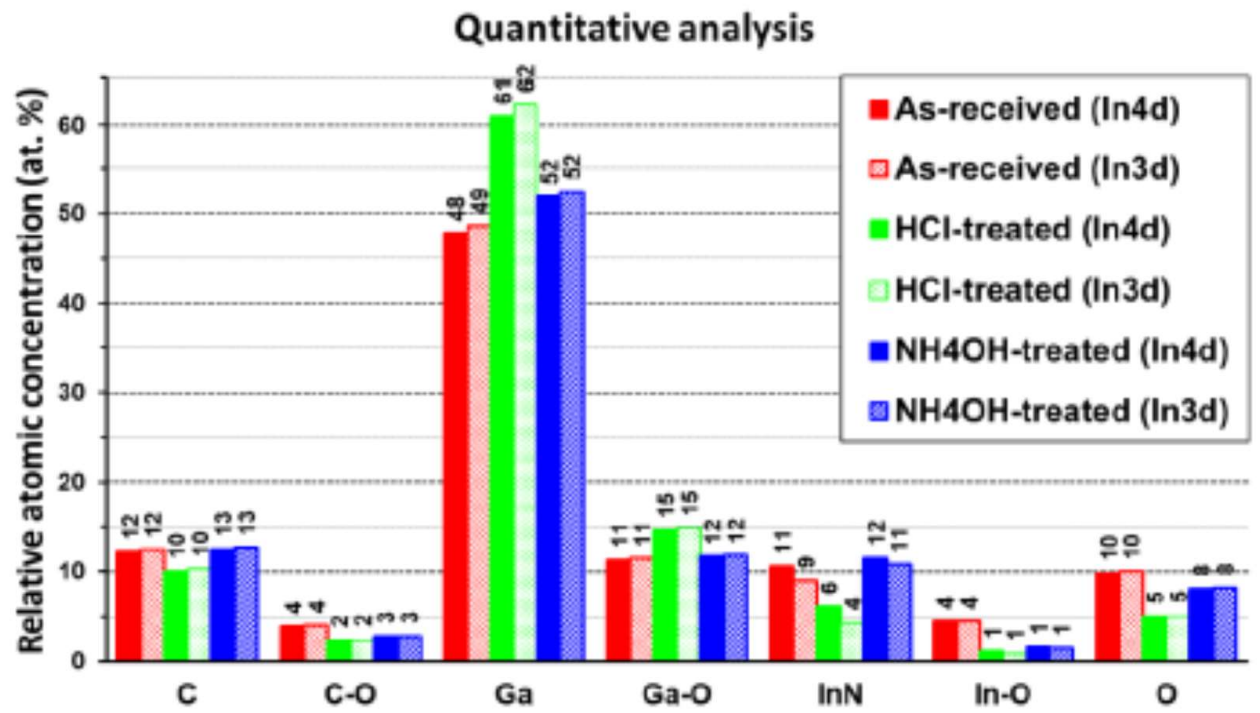

Fig. 3. Relative atomic concentrations estimated from XPS quantitative analysis of samples after $\mathrm{HCl}$ or $\mathrm{NH}_{4} \mathrm{OH}$ treatments, using In $3 \mathrm{~d}$ or In $4 \mathrm{~d}$ lines

Considering that the indium level decrease is larger than oxygen level variations, it appears also that besides indium oxidation decrease, indium preferential etching or desorption at the surface is likely to occur significantly during a $\mathrm{HCl}$ cleaning, whatever it would be oxidized or not.

Besides the oxygen-metalloids component variations of the O1s peak, there is no clear differences at the O1s higher energies between $\mathrm{NH}_{4} \mathrm{OH}$ or $\mathrm{HCl}$ treated samples (fig. 2c). Since the $\mathrm{O} 1 \mathrm{~s}$ composition at the higher energy range could be associated to O-C or O-H species, we could not conclude about surface hydrolysis exclusively based on XPS analysis. 
Similarly, a clear In-OH related component could not be identified at In $3 \mathrm{~d}$ peak's high energies from any samples (fig. 2b), as shown before on some III-V compounds ${ }^{29}$. Provided InGaN alloys could behave in the same way, these results would not suggest indium to significantly bond with $\mathrm{OH}$-related species after $\mathrm{NH}_{4} \mathrm{OH}$ treatment considering XPS analysis scope.

\subsection{Evaluation of sulfur based chemical treatments effectiveness on InGaN surfaces}

The same experiments is performed after implementing $\left(\mathrm{NH}_{4}\right)_{2} \mathrm{~S}$ treatments. As for $\mathrm{HCl}$, a strong decrease of In $4 \mathrm{~d}$ peak near the $\mathrm{Ga} 3 \mathrm{~d}$ spectra is also induced by $\left(\mathrm{NH}_{4}\right)_{2} \mathrm{~S}$ chemical treatments (as shown in figure $4 \mathrm{a}$ ). The decrease is stronger than observed previously with $\mathrm{HCl}$ and seems to be slightly dependent on treatment duration or pre-treatment. Indeed, the quantitative analysis of figure $4 \mathrm{c}$ reports a total indium content reduced to 3 at. $\%$ after the $5^{\prime}\left(\mathrm{NH}_{4}\right)_{2} \mathrm{~S}$ treatment and hardly reaching 2 at.\% after $30^{\prime}\left(\mathrm{NH}_{4}\right)_{2} \mathrm{~S}$ treatment (with or without $\mathrm{NH}_{4} \mathrm{OH}$ pre-treatment). Again, similar trends are obtained whatever the indium photoemission line used for quantification. Therefore, sulfur based chemical treatments such as $\left(\mathrm{NH}_{4}\right)_{2} \mathrm{~S}$ would also induce a preferential etching of indium as observed previously with $\mathrm{HCl}$ solutions.

Moreover, the sulfur is expected to passivate the surfaces, preventing $\mathrm{InGaN}$ atoms from re-oxidizing after treatments. Indeed, a decrease of the oxygen content (fig. 4c) associated with a strong reduction of the low energy oxygen-metalloid related components (fig. $4 \mathrm{~b}$ ) is also observed. With the exception of samples treated with $\left(\mathrm{NH}_{4}\right)_{2} \mathrm{~S}$ only $5^{\prime}$, the $\mathrm{NH}_{4} \mathrm{OH}$ pre-treatment does not seem to induce further oxygen level decrease. Typically, while the total oxygen content is about 10 at. $\%$ for the as-received sample, the latter decreases around $7-8$ at. \% after 5 ' treatment and hardly reaches $5-6$ at. $\%$ after longer treatments.

Considering the ratios of figure $4 \mathrm{~d}$, the oxygen decrease is probably mainly attributed to the decrease of indium and carbon oxidized contributions, the gallium oxidation state being rather stable.

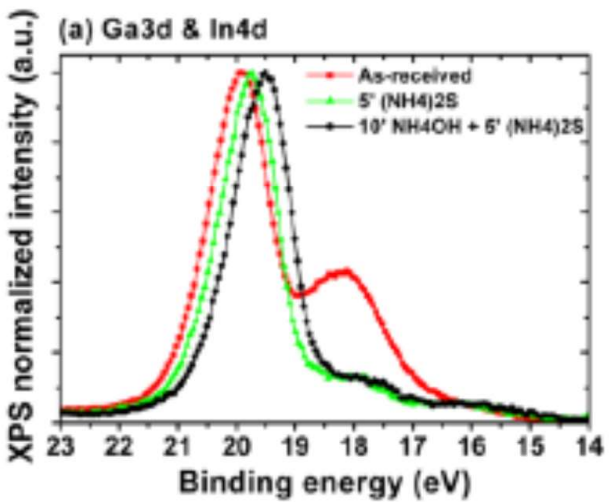

(c) Relative atomic concentration (at. \%)
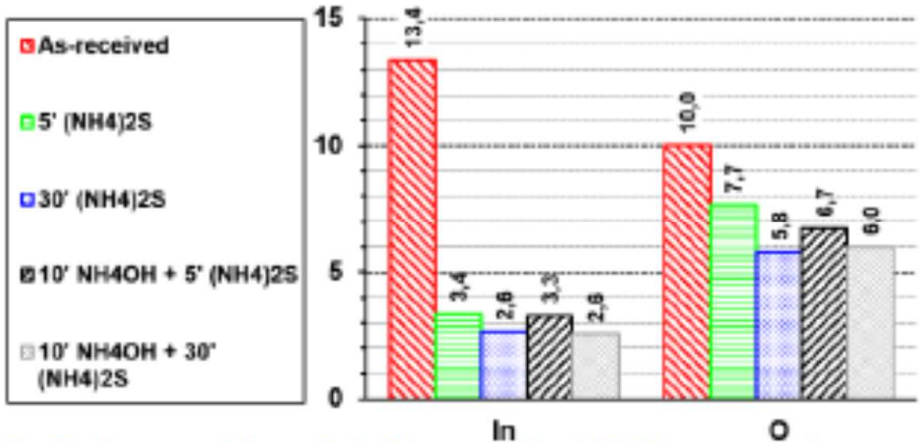

(b) $01 \mathrm{~s}$

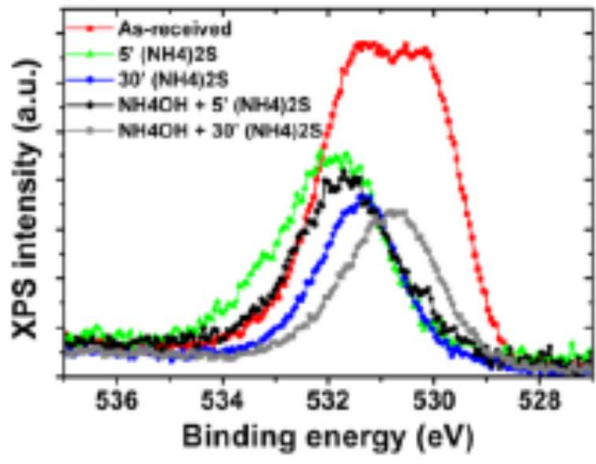

(d) Ratios

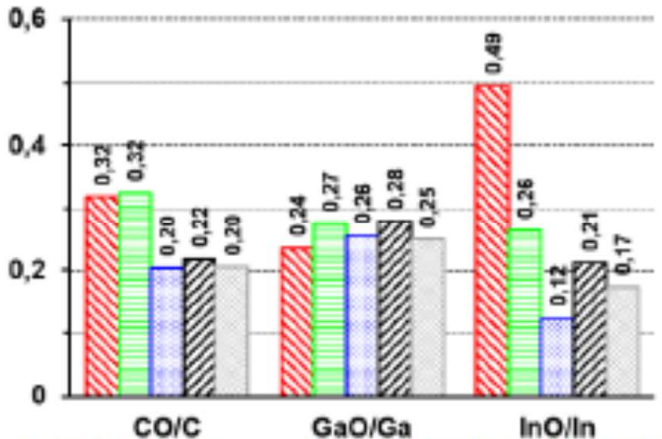

Fig. 4. (a) Superposition of Ga3d normalized XPS spectra of as-received, 5' $\left(\mathrm{NH}_{4}\right)_{2} \mathrm{~S}$ treated and $\mathrm{NH}_{4} \mathrm{OH}+5^{\prime}\left(\mathrm{NH}_{4}\right)_{2} \mathrm{~S}$ treated samples (b) Superposition of O1s XPS spectra of the same samples and of 30' $\left(\mathrm{NH}_{4}\right)_{2} \mathrm{~S}$ treated and $\mathrm{NH}_{4} \mathrm{OH}+30^{\prime}\left(\mathrm{NH}_{4}\right)_{2} \mathrm{~S}$ treated samples (c) Indium and oxygen In3d-based stoichiometric analysis (d) Oxidized/unoxidized components ratio

Sulfur is however hardly detected since no clear S2s or S2p contributions could be observed on these samples. As shown in figure $5 \mathrm{a}$, a slightly broader spectrum would be obtained after $\left(\mathrm{NH}_{4}\right)_{2} \mathrm{~S}$-treatment, if the sample is not rinsed at all. That could suggest the apparition of a small S2p doublet. However, due to the interference with Ga3s components (presumably with the oxide component) the very low intensity S2p doublet identification is quite speculative. Especially 
in comparison to the clear S2p and S2s contributions observed on XPS spectra from the sulfur reference sample (fig. 5a \& 5b). Therefore, considering the oxygen lowering, sulfur might be adsorbed at $\mathrm{InGaN}$ surface after $\left(\mathrm{NH}_{4}\right)_{2} \mathrm{~S}$ treatments but presumably in low proportion and in a state probably quite sensitive to process conditions such as rinsing and to environment. Indeed, several scientific publications highlight the impact of rinsing which tends to remove adsorbed sulfur on $\mathrm{GaN}$ surfaces ${ }^{23}$.

Then, the two distinct components that seems to appear on the S2s line from the sulfur reference sample (fig. 5b) might be representative of In-S or Ga-S bonds. Thus, the gallium or indium oxidized components previously estimated from our decompositions could actually integrate a X-S contribution ( $\mathrm{X}$ being for $\mathrm{Ga}$ or $\mathrm{In}$ ), as already reported in literature ${ }^{30}$. However, further investigations must be conducted in order to really conclude about sulfur bonds nature at In $\mathrm{GaN}$ surfaces.
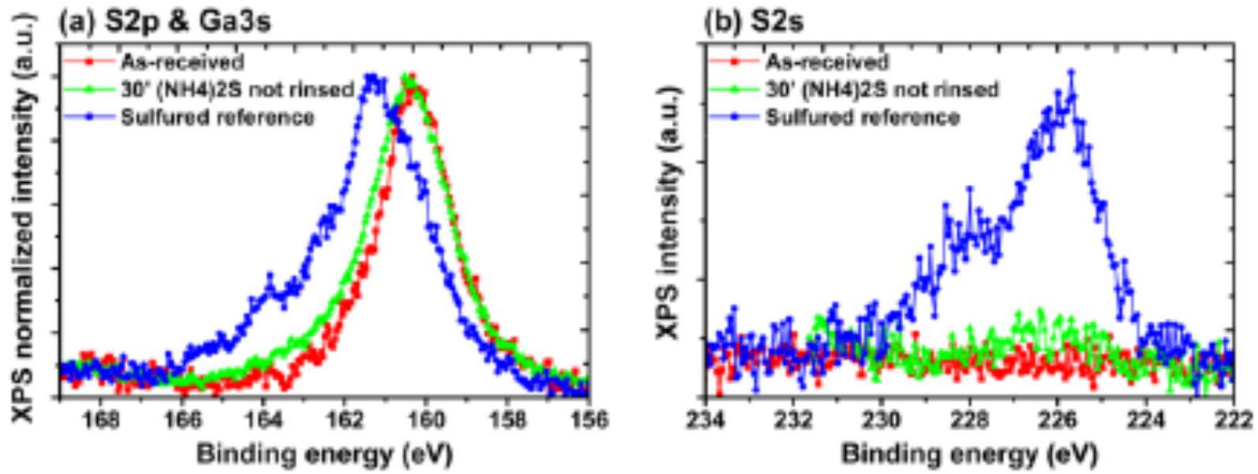

Fig. 5. (a) Superposition of S2p-Ga3s normalized XPS spectra of as-received, 30' $\left(\mathrm{NH}_{4}\right)_{2} \mathrm{~S}$-treated and sulfur reference samples (b) Superposition of $\mathrm{S} 2 \mathrm{~s}$ spectra of the same samples

\subsection{WDXRF measurements}

The complementary WDXRF results from $30^{\prime}\left(\mathrm{NH}_{4}\right)_{2} \mathrm{~S}$ treated samples seem to reveal relatively similar doses of adsorbed sulfur atoms whether the samples were DI water or IPA rinsed (fig. 6). These results are comforted after calibration of the sulfur WDRXF peak position at $110.8^{\circ}$ angle using the $\mathrm{ZnS}$ reference (fig. $6 \mathrm{~b} \& 6 \mathrm{c}$ ). Indeed, the sulfur component is interfering with the $\mathrm{Ga} \mathrm{K} \alpha 4^{\text {th }}$ diffraction order. Based on those measurements, we would evaluate the sulfur dose after these treatments at $5-20 \mathrm{ng} / \mathrm{cm}^{2}$, which could be equivalent to a $\sim 1-4.10^{14}$ at. $\mathrm{cm}^{-2}$ atomic surface density. Therefore, the sulfur proportion on the surface would not be negligible in comparison with the InGaN atomic surface density presumably around $\sim 10^{15}$ at. $\mathrm{cm}^{-2}$.
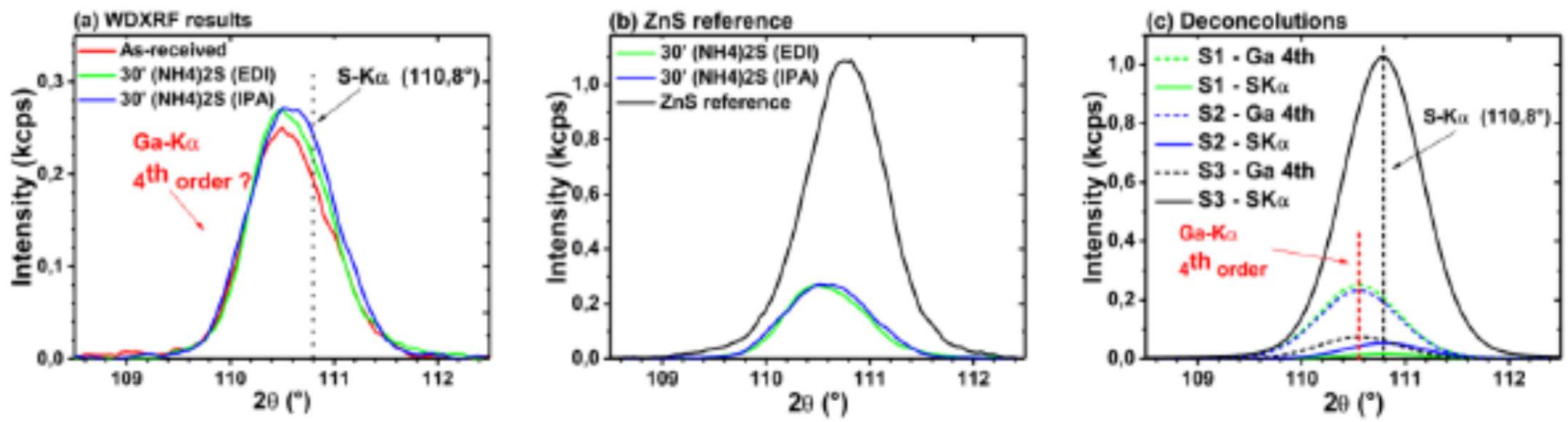

Fig. 6. (a) $\mathrm{S} \mathrm{K} \alpha$ WDXRF measurements spectra of as-received sample and of $30^{\prime}\left(\mathrm{NH}_{4}\right)_{2} \mathrm{~S}$ treated samples with EDI or IPA rinsing (b) comparison with the spectrum obtained from a $\mathrm{ZnS} / \mathrm{InGaN}$ reference (c) spectra deconvolution between the $\mathrm{Ga} \alpha a 4^{\text {th }}$ diffraction order and the S Ka line ( $\mathrm{S} 1: 30^{\prime}\left(\mathrm{NH}_{4}\right)_{2} \mathrm{~S}$ treated with EDI rinsing, S2: 30' $\left(\mathrm{NH}_{4}\right)_{2} \mathrm{~S}$ treated with IPA rinsing; S3: ZnS reference)

Then, WDXRF-based counting measurements after the first TMA cycles were performed in order to indirectly evaluate the surface proportion of $\mathrm{OH}$ related species by TMA grafting. These results display a higher aluminum intensity after a $\mathrm{NH}_{4} \mathrm{OH}$ pre-treatment comparatively to untreated $\mathrm{InGaN}$ surfaces whatever the $\mathrm{ALD}$ cycle number (as displayed in figure 7a). The aluminum atomic surface density after $1 \mathrm{ALD}$ TMA/ $\mathrm{H}_{2} \mathrm{O}$ cycle is estimated to be about $4,2.10^{14}$ at. $\mathrm{cm}^{-2}$ 
without treatment while being $50 \%$ higher $\left(6,3 \cdot 10^{14}\right.$ at. $\left.\mathrm{cm}^{-2}\right)$ using $\mathrm{NH}_{4} \mathrm{OH}$ treatment (fig. $7 \mathrm{~b}$ ). On the contrary, the aluminum dose is always lower in the case of $\mathrm{HCl}$ treated surfaces (typically, $15-20 \%$ lower than for the as-received surface). Therefore, that could be representative of an improved hydroxylation of the InGaN surface after the $\mathrm{NH}_{4} \mathrm{OH}$ treatment.

While the curves slopes seem relatively similar for as-received and $\mathrm{NH}_{4} \mathrm{OH}$ treated samples, the growth rate seems decreased in case of $\mathrm{HCl}$ and $\left(\mathrm{NH}_{4}\right)_{2} \mathrm{~S}$ treated surfaces (fig. $7 \mathrm{~b}$ ). This observation suggests that the growth regime of ' alumina in the first ALD cycles is affected by the initial surface treatment by a mechanism still under investigations.

(a) WDXRF results

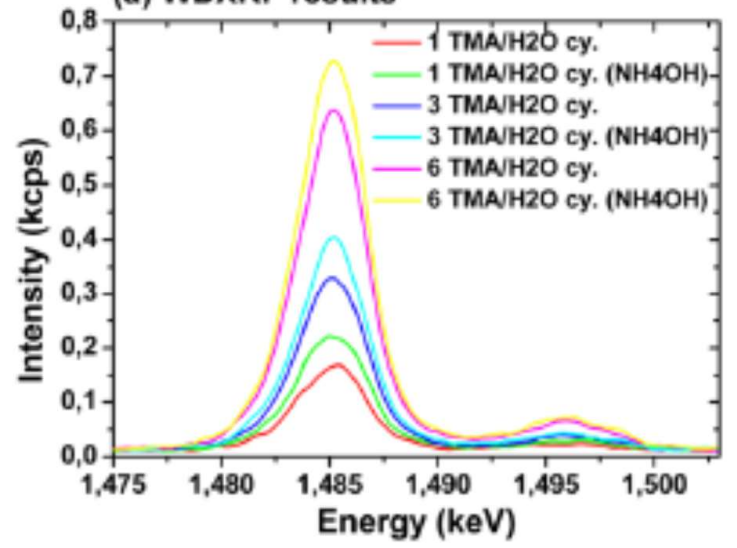

(b) Aluminium dose estimation using WDXRF

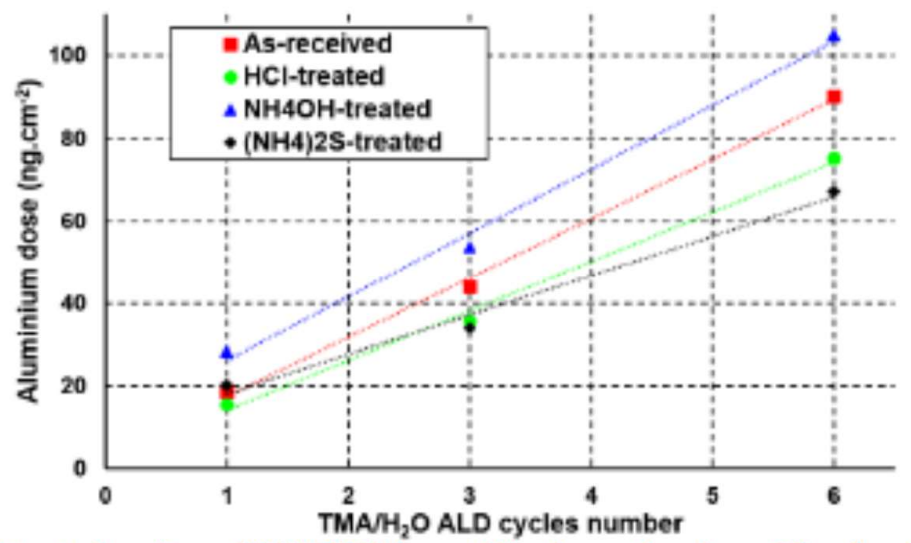

Fig. 7. (a) WDXRF Al intensities for as-received and $\mathrm{NH}_{4} \mathrm{OH}$-treated surfaces (b) WDRXF quantification estimation of the aluminum dose on the surfaces after 1,3 or $6 \mathrm{TMA}\left(1^{\text {st }}\right) / \mathrm{H}_{2} \mathrm{O}$ ALD cycles without surface treatment (as-received), with $\mathrm{HCl}, \mathrm{NH}_{4} \mathrm{OH}$ or $\left(\mathrm{NH}_{4}\right) 2 \mathrm{~S}$ surface treatment

Finally, to summarize the results obtained in this section, the most relevant features are the following:

- $\mathrm{HCl}$ and $\left(\mathrm{NH}_{4}\right)_{2} \mathrm{~S}$ chemical treatments seem to induce a strong preferential etching of indium at the surface and therefore, an InGaN surface band gap increase. Considering LED structures and provided InGaN would behave the same way at LED sidewall, a larger gap could act as a potential barrier for charge carriers.

- $\mathrm{NH}_{4} \mathrm{OH}$ treatments promote hydrolysis of $\mathrm{InGaN}$ surfaces and probably a better nucleation of $\mathrm{Al}_{2} \mathrm{O}_{3}$ thin layer during first cycles of ALD, opening presumably the way to a very good coverage of $\mathrm{InGaN}$ surface.

- $\left(\mathrm{NH}_{4}\right)_{2} \mathrm{~S}$-based chemical treatments are shown to induce oxygen level lowering of the InGaN surfaces. While XPS seems to be only relevant to evaluate the sulfidation effectiveness after higher temperature processes, WDXRF allows the evaluation of sulfur adsorption on $\mathrm{InGaN}$ surfaces after $\left(\mathrm{NH}_{4}\right)_{2} \mathrm{~S}$ treatments at ambient temperature.

\section{XPS STUDY OF THE ALD-AL $\mathrm{O}_{3} /$ INGAN INTERFACE}

In this part, the interfacial properties of $\mathrm{InGaN}-\mathrm{Al}_{2} \mathrm{O}_{3}$ depending on $\mathrm{Al}_{2} \mathrm{O}_{3}$ deposition conditions or annealing will be discussed. The structural properties of the $\mathrm{Al}_{2} \mathrm{O}_{3}$ layer depending on process condition will be evaluated as well.

When the surface is $\mathrm{Al}_{2} \mathrm{O}_{3}$ capped, the $\mathrm{O} 2 \mathrm{~s}$ energy line interferes with the $\mathrm{Ga} 3 \mathrm{~d}$ spectra as illustrated in the figure 8a. Moreover, due to the lower kinetic energy of electrons and thus a higher attenuation, a strong XPS intensity decrease of . the $\mathrm{In} 3 \mathrm{~d}$ line is also induced and tends to reduce the associated analysis precision. Since the O1s line is strongly dominated by $\mathrm{Al}_{2} \mathrm{O}_{3}$ signal (as shown in figures $10 \mathrm{a}$ and $10 \mathrm{~b}$ ), the gallium and indium oxides identification has therefore been done after careful correlation of the different XPS spectra variations.

\subsection{Effect of reactant: ALD versus PEALD}

The ALD of $\mathrm{Al}_{2} \mathrm{O}_{3}$ with $\mathrm{H}_{2} \mathrm{O}$ reactant (weak oxidizer) does not seem to induce a strong modification of the InGaN surface. We still observe an indium depletion since the In $4 \mathrm{~d}$ intensity decreases as observed previously on the $\mathrm{HCl}$ or $\mathrm{NH}_{4} \mathrm{OH}$ treated surfaces only (top of figure $8 \mathrm{a}$ and figure $8 \mathrm{~b}$ ). On the contrary, during the $\mathrm{PEALD}$ of $\mathrm{Al}_{2} \mathrm{O}_{3}$ (strong oxidizer), the $\mathrm{NH}_{4} \mathrm{OH}$ treated surfaces have changed compared to $\mathrm{HCl}$ ones since the In $4 \mathrm{~d}$ component level is no longer distinguished from the PEALD reference (as illustrated by figures $8 \mathrm{a}$, bottom, and $8 \mathrm{~b}$ ). 
Then, if indium is assumed as being the main species sensitive to plasma induced oxidation, the indium depleted surfaces after $\mathrm{HCl}$ treatment would indeed remain in a quite stable state of oxidation whether $\mathrm{ALD}$ or PEALD process. On the contrary, the higher indium proportion from $\mathrm{NH}_{4} \mathrm{OH}$ treated surfaces is expected to be more likely oxidized by the plasma species.
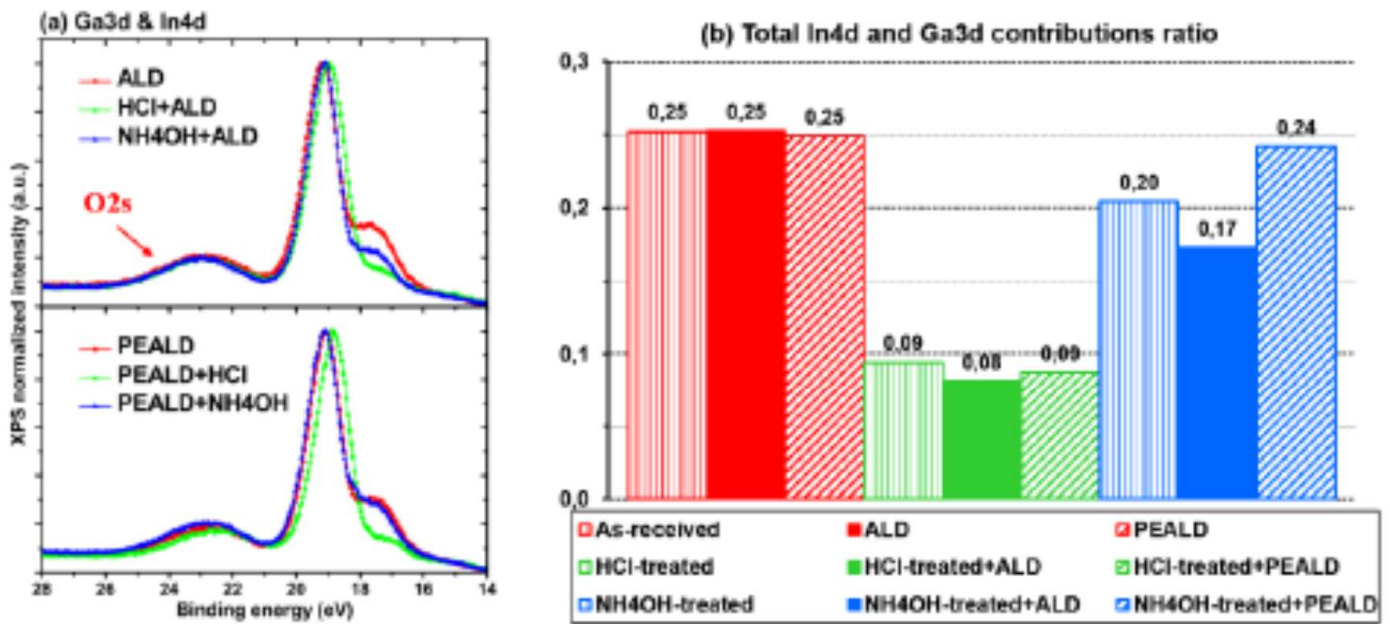

Fig. 8. (a) Superposition of normalized $\mathrm{Ga} 3 \mathrm{~d}-\mathrm{In} 4 \mathrm{~d}$ spectra for $\mathrm{ALD}$ and $\mathrm{PEALD}$ samples without, with $\mathrm{HCl}$ or with $\mathrm{NH}_{4} \mathrm{OH}$ surface treatment (b) $\mathrm{In} 4 \mathrm{~d} / \mathrm{Ga} 3 \mathrm{~d}$ ratios for the same samples in comparison with $\mathrm{Al}_{2} \mathrm{O}_{3}$ free surfaces

\section{5 $\mathrm{ALD}$ of $\mathrm{Al}_{2} \mathrm{O}_{3}$ on sulfur passivation}

If a $30^{\prime}\left(\mathrm{NH}_{4}\right)_{2} \mathrm{~S}$ surface treatment with or without a first $\mathrm{NH}_{4} \mathrm{OH}$ treatment is done before $\mathrm{ALD}$, the quantitative analysis seems to report (figure $9 \mathrm{~b}$ ) similar results than observed previously without the alumina layer. As an example, a similar decrease scale of the indium proportion is observed $(\sim 75 \%)$. However, a slight increase of the O-Al related component from O1s line could be noted for the sample with the double surface treatment, probably related to the increase surface hydrolysis allowed by the first $\mathrm{NH}_{4} \mathrm{OH}$ treatment.

Thus, the ALD does not seem to induce strong modification of the initial state of $\left(\mathrm{NH}_{4}\right)_{2} \mathrm{~S}$-treated surfaces. However, these results do not provide quantitative information concerning sulfur proportion after $\mathrm{Al}_{2} \mathrm{O}_{3} \mathrm{ALD}$ deposition. Considering sulfur was assumed to be adsorbed on $\mathrm{InGaN}$ before deposition, further investigations would determine how sulfur bonds will evolve after $\mathrm{ALD}$ of $\mathrm{Al}_{2} \mathrm{O}_{3}$ and especially if binding state differences with stronger oxidizing process such as PEALD would be visible.
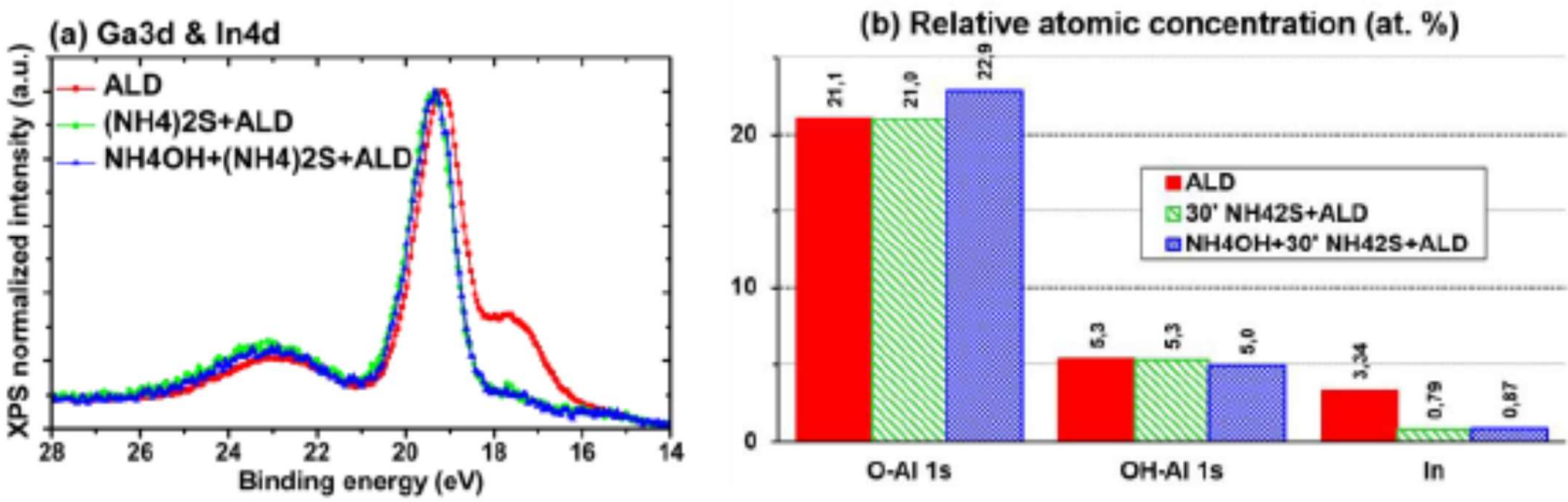

Fig. 9. (a) Superposition of $\mathrm{Ga} 3 \mathrm{~d} \& \mathrm{In} 4 \mathrm{~d}$ normalized XPS spectra of $\mathrm{ALD}-\mathrm{Al}_{2} \mathrm{O}_{3}$ samples without, with a $30^{\prime}$ (NH4)2S or with a $\mathrm{NH}_{4} \mathrm{OH}+30^{\prime}\left(\mathrm{NH}_{4}\right)_{2} \mathrm{~S}$ surface treatment (b) Proportion of O1s components and total indium contribution using In $4 \mathrm{~d}$ line 
The thermal annealing influence on the $\mathrm{Al}_{2} \mathrm{O}_{3} / \mathrm{InGaN}$ interface and $\mathrm{Al}_{2} \mathrm{O}_{3}$ structural properties will now be discussed. Several studies on silicon report the release of hydrogenated species from the $\mathrm{Al}_{2} \mathrm{O}_{3}$ layer, especially hydroxyls, after $400^{\circ} \mathrm{C}$ annealing. This effect has been qualitatively documented on silicon ${ }^{31}$ but similar data does not exist for InGaN surfaces at equivalent annealing temperature.

(a) O1s (before annealing)

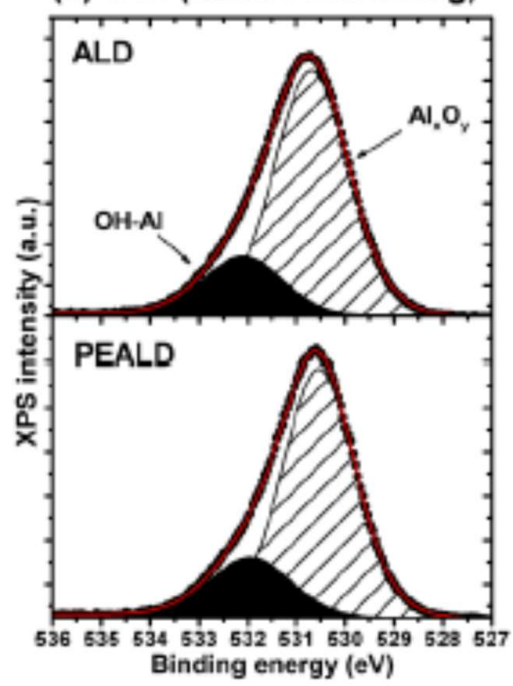

(b) O1s (after annealing)

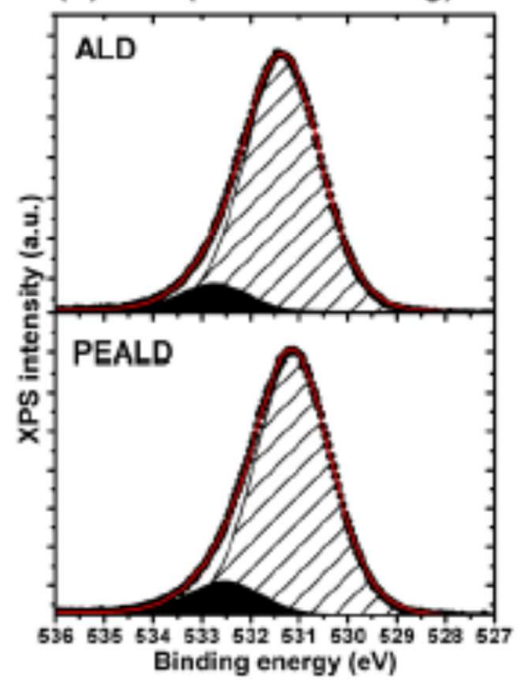

(c) In 3d

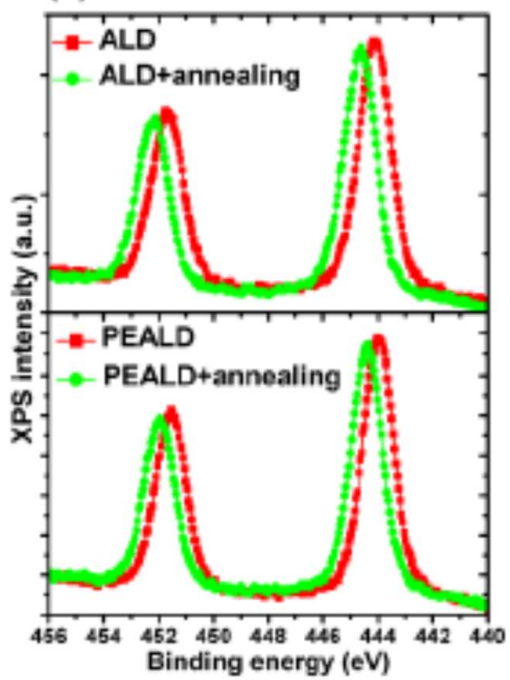

Fig. 10. O1s XPS spectra measured for $\mathrm{ALD}-\mathrm{Al}_{2} \mathrm{O}_{3} / \mathrm{InGaN}$ and $\mathrm{PEALD}-\mathrm{Al}_{2} \mathrm{O}_{3} / \mathrm{InGaN}$ samples before (a) and after (b) $400^{\circ} \mathrm{C}$ thermal annealing (c) superposition of In3d XPS spectra from the same samples

After a $400^{\circ} \mathrm{C}$ thermal annealing, the $\mathrm{O} 1 \mathrm{~s}$ spectra reported in the figure 10 would suggest the $\mathrm{OH}$ related component to be decreased for both ALD and PEALD samples. Moreover, the quantitative analysis (fig. 11b) displays a significant decrease of $\mathrm{Al}-\mathrm{OH} / \mathrm{Al}_{x} \mathrm{O}_{y}$ ratio from $\mathrm{O} 1 \mathrm{~s}$ line. Therefore, thanks to $\mathrm{OH}$ diffusion previously discussed and to thermally activated reactions, aluminum is probably reacting with oxygen to form preferentially $\mathrm{Al}_{\mathbf{x}} \mathrm{O}_{y}$ from $\mathrm{Al}(\mathrm{OH})_{\mathbf{x}}$ related species.

In the same way, the quantitative analysis of figure 11 a seems to report a significant increase of the indium oxidation, as supported by In3d spectra evolution after annealing (fig. 10c). On the contrary, the gallium oxidized and $\mathrm{GaN}$ (-In) components ratio is comparatively much less affected (fig. 11b), which is coherent with the results presented in the first part. Therefore, these results would effectively confirm indium as the main element of the alloy sensitive to oxidizing species, associated in that case with hydroxyls released during the annealing.

(a) In-O (\%)

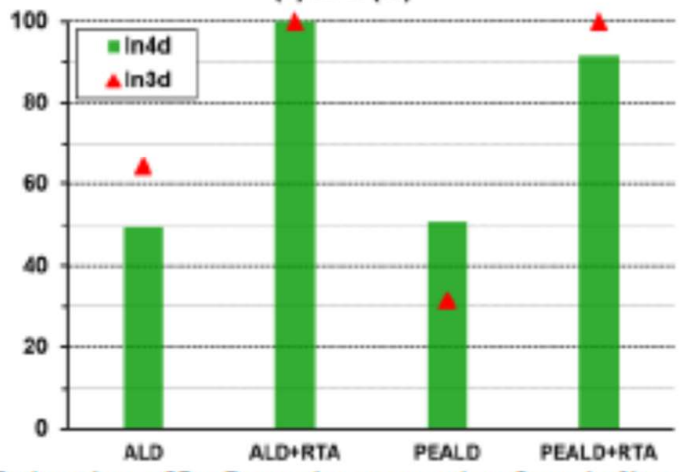

(b) Ratio

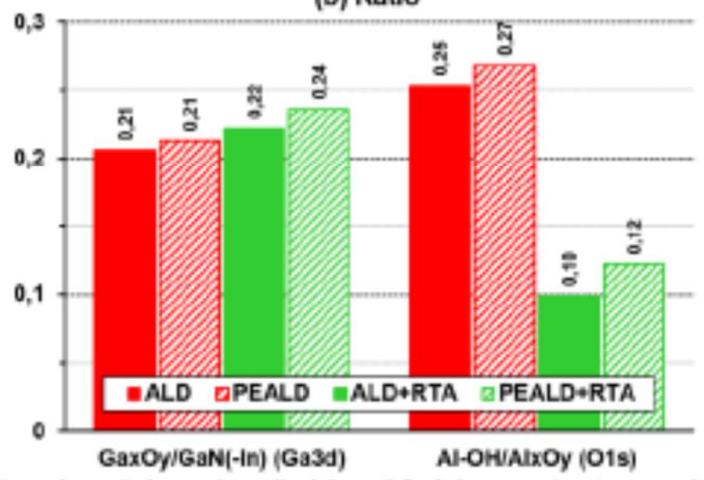

Fig. 11. (a) Estimation of In-O species proportion from indium related peak based on In $4 \mathrm{~d}$ and $\mathrm{In} 3 \mathrm{~d}$ quantitative analysis for annealed $\mathrm{ALD}$ and PEALD samples (b) $\mathrm{Gax} \mathrm{O} / \mathrm{GaN}(-\mathrm{In})$ \& $\mathrm{Al}-\mathrm{OH} / \mathrm{Al}_{x} \mathrm{O}_{y}$ ratio for the same samples (respectively from $\mathrm{Ga} 3 \mathrm{~d}$ and $\mathrm{O} 1 \mathrm{~s}$ lines) 


\section{CONCLUSION}

In this paper, a detailed study of LED QW semiconductor surface properties is reported after various passivation process steps. The XPS analysis suggested indium of InGaN compound to be preferentially etched by several surface treatments such as $\mathrm{HCl}$ or $\left(\mathrm{NH}_{4}\right)_{2} \mathrm{~S}$. Moreover, indium appeared to be probably quite sensitive to oxidation while the oxidation state of gallium seemed globally quite stable through the studied surface treatments, annealing or plasma-based processes.

The sulfidation effect of $\left(\mathrm{NH}_{4}\right)_{2} \mathrm{~S}$ based chemical treatments at ambient temperature provided sulfur surface proportion below XPS sensitivity. However, thanks to the high resolution of WDXRF, we can estimate for the first time adsorbed sulfur in the range of $10^{14} \mathrm{at}_{\mathrm{cm}} \mathrm{cm}^{-2}$, and presumably bonded with gallium or indium by substitution of oxygen.

Moreover, WDXRF measurements highlighted the significance of the chemical pre-treatment or cleaning step before the deposition of a passivating dielectric such as $\mathrm{Al}_{2} \mathrm{O}_{3}$ by $\mathrm{ALD}$. Indeed, contrary to $\mathrm{HCl}$ or $\left(\mathrm{NH}_{4}\right)_{2} \mathrm{~S}, \mathrm{NH}_{4} \mathrm{OH}$ was shown to promote the nucleation of an alumina layer during the first few ALD cycles, presumably thanks to a higher surface hydrolysis. Wettability experiments depending on surface treatments will certainly allow to support the previous assumption.

Complementary WDRXF investigations of $\mathrm{Al}_{2} \mathrm{O}_{3}$ deposition on sulfur treated surfaces would now be of tremendous interest, especially in order to evaluate sulfur bonds stability depending on the oxidizing nature of deposition processes.

Additionally, electrical characterization such as $\mathrm{C}-\mathrm{V}, \mathrm{DL}(\mathrm{O}) \mathrm{TS}$ will certainly allow correlating these qualitative observations with electrically active interface defects, especially after sulfidation related processes. The transposition of all these considerations to $\mu \mathrm{LED}$ sidewalls represents the next challenging step.

\section{ACKNOWLEDGEMENTS}

This work has been performed with the help of the "Plateforme Technologique Amont" de Grenoble, with the financial support of CNRS Renatech network.

Facilities of the NanoCharacterization PlatForm (PFNC) used in this work are supported by the "Recherches Technologiques de Base" Program of the French Ministry of Research.

The authors acknowledge funding from the CleanSky-H2020 HILICO European project (under H2020-EU.3.4.5.6. - ITD Systems, Project ID: 755497).

\section{REFERENCES}

[1] Jiang, H. X., Jin, S. X., Li, J., Shakya, J. and Lin, J. Y., "III-nitride blue microdisplays," Appl. Phys. Lett. 78(9), 13031305 (2001).

[2] Jin, S. X., Li, J., Li, J. Z., Lin, J. Y. and Jiang, H. X., "GaN microdisk light emitting diodes," Appl. Phys. Lett. 76(5), 631-633 (2000).

[3] Jeon, C. W., Choi, H. W. and Dawson, M. D., "Fabrication of matrix-addressable InGaN-based microdisplays of high array density," IEEE Photonics Technology Letters 15(11), 1516-1518 (2003).

[4] Gong, Z., Jin, S., Chen, Y., McKendry, J., Massoubre, D., Watson, I. M., Gu, E. and Dawson, M. D., "Size-dependent light output, spectral shift, and self-heating of $400 \mathrm{~nm}$ InGaN light-emitting diodes," Journal of Applied Physics 107(1), 013103 (2010).

[5] Tian, P., McKendry, J. J. D., Gong, Z., Guilhabert, B., Watson, I. M., Gu, E., Chen, Z., Zhang, G. and Dawson, M. D., "Size-dependent efficiency and efficiency droop of blue InGaN micro-light emitting diodes," Appl. Phys. Lett. 101(23), 231110 (2012).

[6] Dai, L., Zhang, B., Lin, J. Y. and Jiang, H. X., "Comparison of optical transitions in InGaN quantum well structures and microdisks," Journal of Applied Physics 89(9), 4951-4954 (2001).

[7] Choi, H. W., Jeon, C. W., Dawson, M. D., Edwards, P. R., Martin, R. W. and Tripathy, S., "Mechanism of enhanced light output efficiency in InGaN-based microlight emitting diodes," Journal of Applied Physics 93(10), 5978-5982 (2003). 
[29] Martinez, E., Grampeix, H., Desplats, O., Herrera-Gomez, A., Ceballos-Sanchez, O., Guerrero, J., Yckache, K. and Martin, F., "Impact of vacuum anneal at low temperature on Al2O3/In-based III-V interfaces," Chemical Physics Letters 539-540, 139-143 (2012).

[30] Lin, Y.-J. and Lee, C.-T., "Surface analysis of ( $\mathrm{NH}_{4}$ )2Sx-treated InGaN using X-ray photoelectron spectroscopy," Journal of Vacuum Science \& Technology B: Microelectronics and Nanometer Structures Processing, Measurement, and Phenomena 19(5), 1734-1738 (2001).

[31] Dingemans, G., Einsele, F., Beyer, W., van de Sanden, M. C. M. and Kessels, W. M. M., "Influence of annealing and $\mathrm{Al}_{2} \mathrm{O}_{3}$ properties on the hydrogen-induced passivation of the $\mathrm{Si} / \mathrm{SiO}_{2}$ interface," Journal of Applied Physics 111(9), 093713 (2012). 